\title{
Protocol for the Ovine Amniotic Epithelial Cell In Vitro Culture and Differentiation
}

\author{
Hashimita Sanyal*, Annunziata Mauro, Valentina Russo, Paolo Berardinelli, Angelo Canciello, Maura Turriani and \\ Barbara Barboni \\ Faculty of Bioscience and Technology for Food, University of Teramo, Italy
}

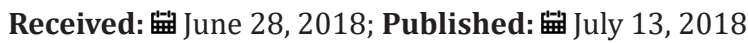

*Corresponding author: Hashimita Sanyal, Università degli Studi di Teramo, Campus universitario di Coste Sant'Agostino, Via R Balzarini 1,64100 Teramo, Italy

\begin{abstract}
Ovine Amniotic epithelial cells (oAEC) are a subject of placental stem cells with great regenerative and immunomodulatory properties. Indeed, oAEC are object of intense study for regenerative medicine thanks to the several advantages in developing pre-clinical studies on a high value translational animal model, such as sheep. For this reason, a critical standardization of in vitro culture practices is fundamental in order to maintain during amplification the oAEC native phenotype, improving both oAEC in vivo therapeutic potential and clinical outcomes. Here, is described an oAEC culture protocol with supplementation of Progesterone and Estradiol hormones, able to modulate the native epithelial phenotype during the in vitro amplification. In addition, it is described the culture protocol that is able to differentiate oAECs towards osteogenic and chondrogenic lineage.

Keywords: Amniotic Epithelial Cells; Progesterone; Estradiol; Osteogenic Differentiation; Chondrogenic Differentiation; Cell Culture; Stem Cells; In Vitro Amplification

Abbreviations: OAEC: Ovine Amniotic Epithelial Cells; AM: Amniotic Membrane; PBMC: Peripheral Blood Mononuclear Cell; EMT: EpithelialMesenchymal Transition; FBS: Fetal Bovine Serum; BSA: Bovine Serum Albumin; $\alpha$-MEM: Alpha Minimum Essential Eagle Medium; TGF- $\beta 1$ : Transforming Growth Factor-beta 1; PBS: Phosphate Buffered Saline; DMSO: Dimethyl Sulphoxide; EDTA: Ethylene Diaminete-tracetic Acid; RT: Room Temperature; MFI: Mean Fluorescence Intensity; DPI: Individual Protection Devices
\end{abstract}

\section{Introduction}

Placenta represents an important source of stem cells, easy to obtain without any ethical concerns [1-3]. Ovine Amniotic epithelial cells (OAEC) are a subset of fetal stem cells located into the inner layer of the amniotic membrane (AM) and are among the most studied placental stem cells because of their peculiar properties $[1,4,5]$. In this regard, oAEC possess an epithelial phenotype and show a typical cobblestone-like morphology. Moreover, oAEC display embryonic markers such as SSEA-1, SSEA-3, SSEA-4, TRA1-60 and TRA-1-81, several surface adhesion molecules (CD29, CD49f, CD58 and CD166) and express pluripotent genes (Oct4, Sox2, Nanog and Tert), while they result negative for CD117 and for any haemopoietic markers (e.g. CD14, CD31 and CD45) $[1,5,6]$. Several evidences have demonstrated the ability of both human and animal derived-AEC to differentiate into derivatives of all three germ layers (endoderm, mesoderm and ectoderm), thus supporting their high plasticity $[1,3,6,7]$. Moreover, since placenta is the natural site where fetus-maternal immune tolerance is played, oAEC display low immunogenicity showing low expression of MHC I antigens and of no detectable levels of MHC II [1,5,6].

Furthermore, oAEC express immunomodulatory and antiinflammatory activities.In fact, it largely demonstrated the ability of oAEC to suppress in vitro the proliferation of stimulated peripheral blood mononuclear cell (PBMC), and to reduce in vivo the infiltration of inflammatory cells as well as to stimulate the activation of M2 macrophages subpopulation [7-11]. Increasing evidences revealed that both human and ovine AEC phenotype can be strongly affected by cultural protocol and in vitro amplification $[4,12,13]$. Indeed, oAEC during in vitro expansion underwent epithelial-mesenchymal transition (EMT), a trans-differentiation process where they lose the epithelial phenotype by progressively acquiring the mesenchymal one [4]. Besides phenotypical shift, oAEC also experienced a dramatic reduction of their immunomodulatory properties, during EMT [4].

Moreover, the in vitro supplementation of Progesterone $\left(\mathrm{P}_{4}\right)-$ the main pregnancy hormone, that has been previously involved in the regulation of EMT [14-17]- is able to prevent the spontaneous EMT in OAEC and preserve the native epithelial properties [4]. It is known that Steroids have a physiological role in modulating pregnancy. However, apart from Progesterone effects, no clear information can be found in literature on the effects of Estradiol $\left(E_{2}\right)$ on AEC native phenotype. Based on this premise, this work describes the protocol based on supplementation of both, $\mathrm{P}_{4}$ and $\mathrm{E}_{2}$ hormones during oAECs in vitro amplification and their differentiation towards osteogenic and chondrogenic lineages. 


\section{Materials}

Use only sterile materials. Prepare all reagents at room temperature and store them at $4{ }^{\circ} \mathrm{C}$ (unless indicated otherwise). Use all reagents at $38{ }^{\circ} \mathrm{C}$. Diligently follow all waste disposal regulations when disposing waste materials.

\section{Reagents and Instruments for Cells Isolation and Culture}

a) Clean with soap and tap water the scalpels, the forceps, the surgical and watchmaker tweezers. Rinse with distilled and double-distilled water and then sterilize in oven. Store in a sterile container. Before the use, sterilize the metallic instruments and with a glass bead sterilizer set at $200{ }^{\circ} \mathrm{C}$ for 15 seconds (Note 1 ).

b) Antibiotics buffer for membrane isolation (use outside the laminal flow hood): dilute $5 \mathrm{~mL}$ of $10.000 \mathrm{UI} / \mathrm{mL}$ PenicillinStreptomycin (Lonza) in $495 \mathrm{~mL}$ of Sodium chloride solution suitable for cell culture (S8776, Sigma) (Note 2). Store at room temperature.

c) Antibiotics buffer for cell isolation (use inside the laminal flow hood): dilute $5 \mathrm{~mL}$ of $10.000 \mathrm{UI} / \mathrm{mL}$ Penicillin-Streptomycin (Lonza) in $495 \mathrm{~mL}$ of Phosphate Buffered Saline (PBS) without calcium, without magnesium, suitable for cell culture (59321C, Sigma) (Note 3). Store at room temperature.

d) Clean with sterilize in oven glass cylinders and beakers.

e) Stereomicroscope.

f) $\quad 0.25 \%$ Trypsin-EDTA (T4049, Sigma).

g) Bürker counting chambers.

h) Trypan Blue solution (T8154, Sigma).

i) Heat-inactivated Fetal Bovine Serum (FBS) (Gibco) (Note 4).

\section{Flow Cytometry Characterization}

a. Un-conjugated primary antibodies marked with FITC by using Zenon Antibody Labelling Kit (Gibco, Invitrogen, Carlsbad, CA, USA), following the manufacturer's instructions.

b. Prepare Washing Buffer by diluting $0.1 \%$ (v/v) of Sodium azideand $0.5 \%(\mathrm{v} / \mathrm{v})$ BovineSerumAlbumin (BSA) in PBS.

c. Prepare Fixation Buffer by diluting $0.5 \%(\mathrm{v} / \mathrm{v})$ of Paraformaldehyde in PBS.

\section{Growth Medium}

Prepare Growth Medium:Alpha minimum essential eagle medium ( $\alpha$-MEM, Lonza) supplemented with 20\% FBS, 1\% Ultraglutamine (Lonza), $10.000 \mathrm{UI} / \mathrm{mL}$ Penicillin Streptomycin

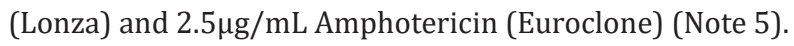

Prepare $\mathbf{P}_{4}$ stock solution:Weight $100 \mathrm{mg}$ of $\mathrm{P}_{4}$ (P8783, Sigma) and transfer in a sterile $15 \mathrm{~mL}$ tube (Note 6). Add absolute ethanol to a volume of $10 \mathrm{~mL}$ and gently mix the solution. Work under fume hood. The concentration of $\mathrm{P}_{4}$ stock solution is $31.8 \mathrm{mM}$. Store a $4^{\circ} \mathrm{C}$.
Prepare $\mathbf{P}_{4}$ working solution: Dilute $5 \mathrm{~mL}$ of $\mathrm{P}_{4}$ stock solution in $5 \mathrm{~mL}$ of absolute ethanol and gently mix the solution. Work under fume hood. The concentration of $\mathrm{P}_{4}$ working solution is $15.9 \mathrm{mM}$. Store a $4^{\circ} \mathrm{C}$.

Prepare $\mathrm{E}_{2}$ stock solution: Weight $100 \mathrm{mg}$ of $\mathrm{E}_{2}$ (E2758, Sigma) and transfer in a sterile $15 \mathrm{~mL}$ tube (Note 6). Add absolute ethanol to a volume of $1 \mathrm{~mL}$ and gently mix the solution. Work under fume hood. The concentration of $\mathrm{E}_{2}$ stock solution is $367 \mathrm{mM}$. Store a $4^{\circ} \mathrm{C}$.

Prepare $\mathbf{E}_{2}$ working solution:Dilute $100 \mu \mathrm{L}$ of $\mathrm{E}_{2}$ stock solution in $9900 \mu \mathrm{L}$ of growth medium and gently mix the solution. Work under fume hood. The concentration of $\mathrm{E}_{2}$ working solution is $3670 \mu \mathrm{M}$. Store a $4^{\circ} \mathrm{C}$.

Add $\mathrm{E}_{2}$ and $\mathrm{P}_{4}$ at final concentrations of $25 \mu \mathrm{M}$, alone or in combination, by discarding the equivalent volume of Growth Medium to maintain the correct steroids concentration. Gently mix the solution (Note 7).

Filter the medium in a $0.22-\mathrm{mm}$ filter and equilibrate in an incubator at $38.5^{\circ} \mathrm{C}, 30$ minutes before the use.

\section{Osteogenic Medium}

Prepare Ascorbic Acid Stock Solution: Weigh 0.289gm of Ascorbic acid (A4403, Sigma) and dissolve in $1 \mathrm{ml}$ of $100 \%$ pure ethanol to obtain a concentration of $1 \mathrm{mM}$.

Prepare B-Glycerophosphate Stock Solution: Weigh 0.216gm of $\beta$-Glycerophosphate(G9422, Sigma) and dissolve in $1 \mathrm{ml}$ of sterile water to prepare a concentration of $1 \mathrm{M}$.

Prepare Dexamethasone Stock Solution: Weigh 0.392gm of Dexamethasone (D4902, Sigma) and dissolve in $1 \mathrm{ml}$ of $100 \%$ pure ethanol to prepare a concentration of $500 \mu \mathrm{M}$.

Prepare $\alpha$-MEM supplemented with $10 \%$ FBS, $1 \%$ Ultraglutamine, $\quad 10.000 \mathrm{UI} / \mathrm{mL} \quad$ Penicillin-Streptomycin and $2.5 \mu \mathrm{g} / \mathrm{mL}$ Amphotericin, $0.05 \mathrm{mM}$ Ascorbic Acid, $10 \mathrm{mM}$ $\beta$-Glycerophosphate and $0.2 \mu \mathrm{M}$ Dexamethasone.

Filter the medium in a $0.22-\mathrm{mm}$ filter and equilibrate in an incubator at $38.5^{\circ} \mathrm{C}, 30$ minutes before the use.

\section{Chondrogenic Medium}

a. $\quad$ Prepare the Ascorbic Acid as in a 2.4.1

b. Prepare Dexamtheasone stock solution as in a 2.4.3.

c. ITS Premix liquid media culture supplement $100 \mathrm{x}$ (Sigma).

d. Prepare Transforming Growth Factor-beta 1, (TGF- $\beta 1$ ) (T1654, Sigma) stock solution: reconstitute the contents of the vial using $0.2 \mathrm{~mm}$ filtered $4 \mathrm{mM} \mathrm{HCl}$ containing $1 \mathrm{mg} / \mathrm{ml}$ of BSA to obtain a TGF- $\beta 1 \mu \mathrm{g} / \mathrm{ml}$ concentration.

e. Prepare $\alpha$-MEM supplemented with $10 \%$ FBS, $1 \%$ Ultraglutamine, $10.000 \mathrm{UI} / \mathrm{mL}$ Penicillin-Streptomycin and $2.5 \mu \mathrm{g} / \mathrm{mL}$ Amphotericin, supplemented with $10 \%$ ITS Premix, 10-7M Dexamethasone, $1 \mu \mathrm{M}$ Ascorbic Acid 1\% sodium pyruvate, and $10 \mathrm{ng} / \mathrm{ml}$ TGF- $\beta 1$. 
f. Filter the medium in a 0.22 -mm filter and equilibrate in an incubator at $38.5^{\circ} \mathrm{C}, 30$ minutes before the use.

\section{Alizarin Red Stain Solution}

Prepare Acetate/Acetic Acid Mix (v/v): weight 1,36gm of sodium acetate (S2889, Sigma) and dissolve $100 \mathrm{ml}$ of distilled water (solution A). Work under chemical flow hood. Also, weight $0.57 \mathrm{ml}$ acetic acid conc. (99,5\%) (A6283, Sigma) and dissolve in $100 \mathrm{ml}$ of distilled water (solution B). Mix $53 \mathrm{ml}$ of solution A with $147 \mathrm{ml}$ of solution $\mathrm{B}$ to obtain a final solution of $\mathrm{pH}$ of 4.2 .

Prepare 2\% Alizarin Red S Solution: weigh 2gm of Alizarin Red S (A5533, Sigma) under chemical hood and dissolve in $100 \mathrm{ml}$ of final Acetate/acetic acid pH 4.2 solution. Filter the solution in a 0.22-mm filter.

\section{Alcian Blue Stain Solution}

Preparation of 3\% Acetic Acid: Add 3ml of Acetic Acid (A6283, Sigma) in $97 \mathrm{ml}$ of distilled water.

Prepare 1\% Alcian Blue Stain Solution: weigh 1gm of Alcian blue 8 GX (A9186, Sigma) and dissolve in 100ml di 3\%Acetic acid under chemical flow hood. Filter the solution in a $0.22-\mathrm{mm}$ filter.

\section{Immuno Fluorescence}
a) $35 \mathrm{~mm}$ petri dish.
b) Sterile coverslips.
c) $4 \%(\mathrm{v} / \mathrm{v})$ paraformaldehyde in PBS (CAS 30525-89-4).
d) $\quad 0.2 \%(\mathrm{v} / \mathrm{v})$ Triton $\mathrm{X}-100$ in PBS.
e) $5 \%(\mathrm{w} / \mathrm{v}) \mathrm{BSA}$ in PBS and $1 \%(\mathrm{w} / \mathrm{v}) \mathrm{BSA}$ in PBS.
f) Anti-Cytokeratin-8 (Abcam), anti- $\alpha$-SMA (Abcam) primary antibodies.

g) Cy3 and Alexa Fluor 488 conjugated anti-mouse secondary antibodies.
h) 4', 6-diamidino-2-phenylindole (DAPI, Vectastain).
i) Fluoromount (Sigma Chemical Co.).

\section{Freezing Medium}

a) Prepare the Freezing Medium solution composed by $10 \%$ (v/v) of dimethyl sulphoxide (DMSO) $90 \%$ (v/v) of FBS. Filter the solution with a $0.22-\mathrm{mm}$ filter.

b) $1.8 \mathrm{~mL}$ Nunc Cryotubes (V7634, Sigma)

c) Thermo Scientific Mr. Frosty Freezing Container filled with isopropanol.

\section{Methods}

Carry out all procedures at room temperature unless otherwise specified.

\section{OAEC Isolation}

a) Carefully prepare the uterus and the incision site with denatured alcohol (Note 8).

b) Open the uterus wall with the aid of surgical forceps.
Afterwards, gently separate placenta from the uterus by manually detaching the cotyledons from caruncles.

c) Once the placenta is isolated from the rest of the uterus, roughly peel off with surgical and watchmaker tweezers the chorioallantois from the amnion.

d) Cut amnion pieces with the aid of surgical tweezers and forceps and put them into Antibiotics buffer for membrane isolation.

e) Move the amnion pieces under laminal flow hood and put them into Antibiotics buffer for cell isolation.

f) Working into a $10 \mathrm{~cm}$ petri dish filled with Antibiotics buffer for cell isolation, divide the amnion in smaller pieces of about $3-5 \mathrm{~cm}$ of length by using sterile watchmaker tweezer and scalpel.

g) Manipulate under a stereomicroscope in order to finely remove the residual parts of chorioallantois from the amnion with the aid of fine watchmaker forceps (Note 9).

h) Dissect amnion with sterile watchmaker tweezer and scalpel to get tissue pieces of about $1 \mathrm{~cm} 2$ or less.

i) Rinse three times for 15 minutes the amnion pieces with Antibiotics buffer for cell isolation.

j) Incubate amnion pieces into trypsinization flasks (Note 10). Add $0.25 \%$ TrypsinEDTA solution and a magnetic stir bar. Place the trypsinization flasks on a magnetic stirrer in $38{ }^{\circ} \mathrm{C}$ water bath for 30 minutes, with consistent agitation (Note 11).

k) Add FBS $10 \%(\mathrm{v} / \mathrm{v})$ to cell suspension in order to inactivate trypsin. Collect cell suspension, filter through a 40 $\mathrm{mm}$ cell filter and pour into a $50 \mathrm{~mL}$ tube. Centrifuge the cell suspension at 2500 rpm for 10 minutes.

I) Discard the supernatant and resuspend the pellet in prewarmed and equilibrated Growth Medium.

m) Dilute 1:2 cell suspension in Trypan Blue solution into a 0.5 micro tube and gently pipette the suspension. Count the cell suspension by using a Bürker counting chambers (Note 12).

n) Seed the cells at the final concentration of $3 \times 103$ cells/ $\mathrm{cm} 2$ in Growth Medium supplemented with $25 \mu \mathrm{M}$ of $\mathrm{E}_{2}$ and $\mathrm{P}_{4^{\prime}}$ alone or in combination (Note 13).

o) Carefully mix the dish by gentle agitation to obtain an equal seeding of the cells.

p) Incubate the culture dish in incubator at $38.5{ }^{\circ} \mathrm{C}$ in $5 \%$ $\mathrm{CO}_{2}$.

\section{Flow Cytometry Characterization}

a) Stain $5 \times 105$ cells/sample by incubating them with $100 \mu \mathrm{L}$ of $20 \mathrm{mM}$ ethylenediaminetetracetic acid (EDTA) at $37^{\circ} \mathrm{Cfor} 10$ minutes.

b) Wash in $3 \mathrm{~mL}$ of Washing Buffer and centrifuge at $4{ }^{\circ} \mathrm{C}, 400$ $\mathrm{x} g$ for 8 minutes. 
c) Resuspend cell pellet in $100 \mu \mathrm{L}$ Washing Buffer containing the appropriate dilution of surface antibody (Table 1) and incubate for 30 minutes at $4{ }^{\circ} \mathrm{C}$ in the dark.

Table 1: Summary of Primary Antibodies Used in Cytoflourimetric Analysis.

\begin{tabular}{|c|c|c|c|}
\hline Antigen & $\begin{array}{c}\text { Conjugated } \\
\text { Fluorescent } \\
\text { Probe }\end{array}$ & $\begin{array}{c}\text { Company } \\
\text { Details }\end{array}$ & \\
\hline $\begin{array}{c}\text { Hemopoietic } \\
\text { markers } \\
\text { CD14 }\end{array}$ & FITC & $\begin{array}{c}\text { LifeSpan } \\
\text { Biosciences }\end{array}$ & Seattle, WA, USA \\
\hline CD31 & FITC & AbD Serotec & Oxford, UK \\
\hline CD45 & FITC & AbD Serotec & Oxford, UK \\
\hline $\begin{array}{c}\text { Adhesion } \\
\text { molecules } \\
\text { CD29 }\end{array}$ & VITC & Ancell & Wu, USA \\
\hline CD49f & & Abcam & Cambridge, UK \\
\hline CD166 & & Abcam & Cambridge, UK \\
\hline $\begin{array}{c}\text { Stemness } \\
\text { markers } \\
\text { CD117 }\end{array}$ & PE & $\begin{array}{c}\text { Becton } \\
\text { Dickinson }\end{array}$ & BD, San Jose, CA \\
\hline SOX2 & & Calbiochem & Gibbstown, NJ \\
\hline OCT 4 & & Chemicon Int. & Billerica, MA \\
\hline TERT & & & \\
\hline NANOG & & & WSA \\
\hline
\end{tabular}

d) Wash with $3 \mathrm{~mL}$ of Washing Buffer, centrifuge at $4{ }^{\circ} \mathrm{C}, 400$ $\mathrm{x} g$ for 8 minutes.

e) Suspend cells samples with $1 \mathrm{~mL}$ of Fixation Buffer and incubate for 5 minutes at room temperature (RT).

f) Wash cell samples by centrifuging at $4{ }^{\circ} \mathrm{C}, 400 \mathrm{x}$ g for 8 minutes and store at $4{ }^{\circ} \mathrm{C}$ in the dark until the acquisition.

g) Analyze cell samples on a FACSCalibur flow cytometer, using CellQuestTM software (both from BD Biosciences).

h) Use as quality control Rainbow Calibration Particles and CaliBRITE beads (both from BD Biosciences) (Note 14).

i) Analyze data by using FlowJo® software (TreeStar, Ashland, OR). Calculated the Mean Fluorescence Intensity (MFI) ratio dividing the MFI of positive events by the MFI of negative events [18].

\section{Culture, Passing and Cryopreservation of oAEC}

a. Change the Growth Medium each 2 days (Note 15).

b. Split the cells when they reach about $80 \%$ confluency (Note 16).

c. Discard the Growth Medium and rinse three times with PBS without calcium, without magnesium (Note 17).

d. Discard the PBS and then add $0.25 \%$ Trypsin-EDTA by ensuring that trypsin covers the entire surface of the culture dish. Place the cells at $38.5{ }^{\circ} \mathrm{C}$ in $5 \% \mathrm{CO}_{2}$ for $8-10$ minutes (Note 18). e. Inactivate the Trypsin with Growth Medium and pipette vigorously the cell suspension to detach cells (Note 19). Collect cells in a sterile tube and centrifuge the suspension at $2500 \mathrm{rpm}$ for 10 minutes.

f. Discard the supernatant and resuspend the pellet in prewarmed and equilibrated Growth Medium.

g. Perform the cell count and seed the cells at the same density $\left(3 \times 10^{3}\right.$ cells $\left./ \mathrm{cm}^{2}\right)$ in Growth Medium supplemented with $25 \mu \mathrm{M}$ of $\mathrm{E}_{2}$ and $\mathrm{P}_{4}$ alone or in combination for the next culture passage.

h. Incubate the culture dish at $38.5^{\circ} \mathrm{C}$ in $5 \% \mathrm{CO}_{2}$.

i. Centrifuge the rest of oAEC not seeded at 2500rpm for 10 minutes. Discard the supernatant and resuspend the pellet in Freezing Medium. Carefully mix the cell suspension.

j. Distribute $1 \mathrm{~mL}$ of cell suspension for each $1.8 \mathrm{~mL}$ Nunc $\bigotimes$ CryoTubes区.

k. Put the Nunc $\bigotimes$ CryoTubes $\bigotimes$ into a Mr. Frosty $\bigotimes$ Freezing Container. Store the cells at $-80{ }^{\circ} \mathrm{C}$ for 1 day.

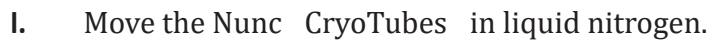

\section{Osteogenic Culture Differentiation of oAEC}

a. Culture oAECs as described in paragraph 3.3.1 until 3.3.5.

b. Discard the Growth Media and resuspend the cells pellet in pre-warmed and equilibrated Osteogenic Differentiation Medium.

c. Perform the cell count and seed the cells at the same density $\left(3 \times 10^{3}\right.$ cells $\left./ \mathrm{cm}^{2}\right)$ in Osteogenic Differentiation Medium.

d. Culture cells in culture dish at $38.5{ }^{\circ} \mathrm{C}$ in $5 \% \mathrm{CO}_{2}$ for 21 days changing the Osteogenic Differentiation Medium each 2 days.

\section{Chondrogenic Culture Differentiation of oAEC}

a. Culture oAECs as described in paragraph 3.3.1 until 3.3.5.

b. Discard the supernatant and resuspend the cells pellet in pre-warmed and equilibrated Chondrogenic Differentiation Medium.

c. Perform the cell count and seed the cells at the same density $\left(3 \times 10^{3}\right.$ cells $\left./ \mathrm{cm}^{2}\right)$ in Chondrogenic Differentiation Medium.

d. Culture cells in culture dish at $38.5^{\circ} \mathrm{C}$ in $5 \%$ CO2 for 21 days changing the Chondrogenic Differentiation Medium each 3-4 days.

\section{Assessing Epithelial Phenotype by Immunofluorescence}

a) Plate oAEC in $35 \mathrm{~mm}$ petri dish with a sterile glass coverslip on the bottom (Note 20). Culture the cells until the reaching of 50-60\% confluency (Note 21 ).

b) Rinse three times with PBS with calcium, with magnesium. 
c) Fix oAEC in $4 \%(\mathrm{v} / \mathrm{v})$ paraformaldehyde in PBS for $10 \mathrm{~min}$ at RT (Note 22). Rinse three times with PBS.

d) Permeabilize with $0.2 \%(\mathrm{v} / \mathrm{v})$ Triton X-100 in PBS for $10 \mathrm{~min}$ at RT, with gentle agitation.

e) Block non-specific sites with $5 \%(\mathrm{w} / \mathrm{v})$ BSA in PBS for 1 hour at RT, with gentle agitation.

f) Incubate with anti-Cytokeratin-8 (1:200) or anti- $\alpha$-SMA (1:200) primary antibodies diluted in $1 \%$ (w/v) BSA/PBS, overnight at $4{ }^{\circ} \mathrm{C}$ in gentle agitation (Note 23 ).

g) Rinse three times with PBS at RT, with gentle agitation.

h) Incubate with Cy3 (anti- $\alpha$-SMA) or Alexa Fluor 488 (antiCytokeratin-8) conjugated anti-mouse secondary antibodies diluted 1:200 in $1 \%(\mathrm{w} / \mathrm{v})$ BSA/PBS for $40 \mathrm{~min}$ at RT in the dark, with gentle agitation.

i) Staining nuclei with DAPI used at the final dilution of 1:5000 in PBS for 5 minutes in the dark, with gentle agitation.

j) Mount coverslips with Fluor mount and analyze cell samples with the aid of a fluorescent microscope equipped with a CCD camera, configured for fluorescence microscopy and interfaced to a computer workstation, provided with an interactive and automatic image analyzer. Digital images are acquired using standard filters setup for Cy3, Alexa Fluor 488 or DAPI.

k) Determine the percentage of Cytokeratin- 8 and $\alpha$-SMA positive cells by counting at least 100 cells for each sample (Note 24).

\section{Assessing Osteogenic Mineralization by Alizarin Red S Stain}

a. Plate oAEC in $35 \mathrm{~mm}$ petri dish as described in a paragraph 3.4 .

b. Rinse Petri dish three times with PBS without calcium and magnesium.

c. Stain the cultured cells for $3 \mathrm{~h}$ in $2 \%$ of Alizarin in Acetate / acetic acid pH 4.2 (1 $\mathrm{ml}$ in $35 \mathrm{~mm}$ Petri dish).

d. Wash in distilled water for $5 \mathrm{~min}$ and mount coverslips with 10-15 $\mu$ l of Mounting Media (C9368, Sigma) for microscopic observation.

\section{Assessing Chondrogenic Pretoeglycans and Aggrecans by Alcian Blue Stain}

a. Plate oAEC in $35 \mathrm{~mm}$ petri dish as described in a paragraph 3.5 .

b. Rinse Petri dish three times with PBS without calcium and magnesium.

c. Stain cells for $2 \mathrm{~h}$ in $1 \%$ Alcian blue $8 \mathrm{GX}$ in $3 \%$ acetic acid (1ml in 35mm Petri dish).

d. Wash in 3\% Acetic Acid for 3-5 minutes, followed by 1 wash in distilled water. Mount coverslips with $10-15 \mu$ l of Mounting Media (C9368, Sigma) for microscopic observation.

\section{Note}

1. Do not exceed 15 seconds of sterilization to avoid the metal from reaching too high temperature. High temperature could damage the tissue and negatively influence the yield of cells isolation because it increases the percentage of cell death. Moreover, metal objects exposed to high temperature became incandescent and could cause damage to the operators.

2. Prepare the Antibiotics buffer for membrane isolation under a laminal flow hood. Use only sterile materials. Sodium chloride solution should be stored at room temperature to avoid precipitation of the salt.

3. Prepare the Antibiotics buffer for cell isolation under a laminal flow hood. Use only sterile materials. PBS without calcium, without magnesium should be stored at room temperature to avoid precipitation of the salts. PBS without calcium, without magnesium guarantees good results in term of oAEC detach from amniotic membrane, as adhesion proteins require divalent cations for proper function.

4. Inactive $\mathrm{FBS}$ at $56^{\circ} \mathrm{C}$ in the water bath for 30 minutes.

5. Warm all reagents to $38^{\circ} \mathrm{C}$ in the water bath in order to reach ovine cell physiological temperature.

6. $\mathrm{E}_{2}$ and $\mathrm{P}_{4}$ are carcinogen and toxic for the reproduction (H351, H360 risk category). Use Individual Protection Devices (DPI) such as safety glass clear lens, molded disposable mask with valve, gloves and lab coat. Wear the mask when weighting the steroids. To avoid exposing the steroids to co-workers, weight them directly in a $15 \mathrm{~mL}$ tube (by storing the container weight as tare weight) and close the tube when transporting it to the fume hood. Add $10 \mathrm{~mL}$ of absolute ethanol and filter the solution before storage. The used $15 \mathrm{~mL}$ tube should be disposed as hazardous waste.

7. Absolute ethanol is generally used as solvent for dissolving several drugs. However, it is possible that high concentrations of absolute ethanol can negatively influence cell culture. In agreement with others investigators, the final concentration of absolute ethanol in cell culture medium should be about 0.1 $\%$. The high dilution of $\mathrm{P}_{4}$ working solution selected (1:625) allow to obtain exiguous volume of absolute ethanol into Growth Medium. In these experimental conditions, the final concentration of absolute ethanol in the medium will be about $0.16 \%$.

8. The ovine uteri are collected at slaughterhouse. For this reason, a proper sterilization of the incision site and the surgical instruments is strongly recommended because significantly reduces the amount of contamination. Since the uteri are collected from animals intended for food, all the animals are preventively subjected to a prophylaxis against the principal sexually transmitted infections.

9. Ruminants are characterized by the presence of a chorioallantois, which is established by fusion between the allantoic wall and chorion. Chorioallantois is often recognizable by the presence of blood vessels. On the other hand, in 
Ruminants epithelial layer of the amnion is often recognizable by the presence of amniotic plaques, that are stratified glycogenrich epithelial elevations from the inside inner epithelium of the amnion [19].

10. Do not fill the trypsinitazion flask with a high number of AM pieces in order to allow a proper cell separation. Put about 10-15 pieces of AM for each $125 \mathrm{~mL}$ trypsinization flask.

11. Better results are obtained by using $15-20 \mathrm{~mL}$ of 0.25 $\%$ Trypsin-EDTA solution. Moreover, select a proper speed of magnetic stirrer (200-230rpm) to allow a consistent agitation of magnetic stir.

12. Since oAEC tend to form clusters in suspension, vigorously pipette the cell suspension before performing the dilution with Trypan Blue solution. Count the cell suspension at least three time to be sure of the result of the counting. Indeed, oAEC are quite sensible to cell density and improper cell counting or seeding can negatively influence their growth.

13. It has been demonstrated that P4concentration allows the preservation of the native epithelial phenotype of oAEC. Indeed, when cultured in absence of $\mathrm{P}_{4}$ (standard cultural conditions) oAEC experienced epithelial-mesenchymal transition (EMT) in culture. In particular, it is previously demonstrated that oAEC undergo EMT after three cultural passages [4]. Conversely, when the culture medium is supplemented with $25 \nabla \mathrm{M}$ of $\mathrm{P}_{4}$ oAEC preserved their native epithelial phenotype in a longterm culture.

14. Contains a mixture of Rainbow Calibration Particles (approximately $1 \times 107$ particles/mL) that are designed for routine calibration of flow cytometers and contain a mixture of fluorophores that are excited at any wavelength from 365 to $650 \mathrm{~nm}$. Before use, mix or resuspend the particles by vortexing. Dilution of 3 - 5 drops of particles to $1 \mathrm{~mL}$ of sheath fluid will provide an adequate number of particles for flow cytometric analysis. Exclude debris from the analysis by gating on morphological parameters (lymphocyte gate); record 20.000 non-debris events in the morphological gate for each sample.

15. At the first passage, the percentage of oAEC that adhere at the culture dish is lower than the number of seeded cells. For this reason, it is suggested to change the Grow Medium after 3 days at beginning of the cell culture in order to allow the cells to properly adhere.

16. Generally, oAEC take about 10-12 days to reach $80 \%$ confluency when are freshly isolated. After the first cultural passage, oAEC take about 4-5 days to reach $80 \%$ confluency. It is not recommended to exceed the $80 \%$ confluency to avoid the morphological changes due to epithelial-mesenchymal transition.

17. The wash steps remove any traces of serum, divalent cations that would inhibit the dissociation action of trypsin.

18. For the epithelial nature of oAEC, they are usually difficult to detached from the culture dish. For this reason, it is recommended to use $0.25 \%$ instead of $0.05 \%$ of TrypsinEDTA. Moreover, in order to proper detach cells and increase the yield of trypsinitazion, incubate the culture dish for 8-10 minutes and check them microscopically every 3-4 minutes. It is advisable to gently tap the dish in order to facilitate cell detachment.

19. Add the equivalent volume of Growth Medium to the cells suspension to inactivate the trypsin action. Since Growth Medium contains $20 \%$ FBS, using an equal volume of it respect to trypsin allow to obtain a final dilution of $10 \%$ FBS. As epithelial cells, oAEC tend to from clusters when are in suspension. These clusters are generally hardly to dissociate and can negatively influence cell count because they can be formed by a high number of cells. For this reason, vigorously pipette of cell suspension at least 25-30 times to facilitate cluster dissociation.

20. Put glass coverslips $(22 \times 22 \mathrm{~mm})$ into a beaker and sterilize in oven at $180{ }^{\circ} \mathrm{C}$ for 2 hours. Afterwards, immerse glass coverslips in absolute ethanol under laminal flow hood and let them became air dry. Put the coverslip into a $35 \mathrm{~mm}$ petri dish with the aid of sterile watchmaker tweezer.

21. A confluency greater than $60 \%$ could negatively influence cell fixation and interfere with the interpretation of the data due to the overlapping of fluorescent signals.

22. Be careful in handling paraformaldehyde because is flammable and may cause skin irritation, allergic skin reaction, eye damage and respiratory irritation. Use personal protective equipment and avoid contact with skin and eye. In order to avoid the formation of dust and aerosol, work under a fume hood.

23. Careful aspirate the excess of PBS from the edges of the petri dish leaving a thin layer of PBS only on the coverslip. It could be helpful to use a PAP pen (ab2601) which allow to create hydrophobic barrier when a circle is drawn around a specimen on a slide. It is recommended to carefully add a drop of approximately 50-60खL of diluted primary antibodies. Cytokeratin-8 is an intermediate filament protein characteristic of the epithelial cells and is considered one of the first markers that disappears in the context of EMT [20]. On the contrary, 囚-SMA is an actin isoform expressed by vascular smooth muscle, myoepithelial and mesenchymal cells and is well defined as a marker of an advanced stage of EMT [21].

24. Snap micrographs with low magnification in order to count at least 100 cells in each field. To determine the total number of cells per field, count all the nuclei counterstained with DAPI. In order to assess the percentage of epithelial or mesenchymal cells, count the Cytokeratin-8 or the $\triangle$-SMA positive cells and divide the obtained number by the total number of nuclei and then multiply the result by 100 .

\section{Acknowledgment}

Rep-Biotech 675526, Marie-Sklodowska Curie Actions, funded by the Horizon 2020 Program of the European Union 


\section{References}

1. Mattioli M, Gloria A, Turriani M, Annunziata Mauro, Valentina Curini, et al. (2012) Stemness characteristics and osteogenic potential of sheep amniotic epithelial cells. Cell Biol Int 36(1): 7-19.

2. Murphy SV, Atala A (2013) Amniotic Fluid and Placental Membranes: unexpected sources of highly multipotent cells 31(1): 62-68.

3. Koike C, Zhou K, Takeda Y, Moustafa Fathy, Motonori Okabe, et al. (2014) Characterization of Amniotic Stem Cells. Cell Reprogram 16(4): 298-305.

4. Canciello A, Russo V, Berardinelli P, Nicola Bernabò, Aurelio Muttini, et al. (2017) Progesterone prevents epithelialmesenchymal transition of ovine amniotic epithelial cells and enhances their immunomodulatory properties. Sci Rep 7: 3761.

5. Barboni B, Russo V, Berardinelli P (2016) Applications of PlacentaDerived Cells in Veterinary Medicine. In Parolini O (Eds.) Placenta Tree Life. CRC Press, Florida, USA, pp. 217-284.

6. Barboni B, Curini V, Russo V, Annunziata Mauro, Oriana Di Giacinto, et al. (2012) Indirect Co-Culture with Tendons or Tenocytes Can Program Amniotic Epithelial Cells towards Stepwise Tenogenic Differentiation. PLoS One.

7. Barboni B, Mangano C, Valbonetti L, Giuseppe Marruchella, Paolo Berardinelli, et al. (2013) Synthetic Bone Substitute Engineered with Amniotic Epithelial Cells Enhances Bone Regeneration after Maxillary Sinus Augmentation. PLoS One 8: e63256.

8. Barboni B, Russo V, Curini V, Alessandra Martelli, Paolo Berardinelli, et al. (2014) Gestational stage affects amniotic epithelial cells phenotype, methylation status, immunomodulatory and stemness properties. Stem Cell Rev Reports 10(5): 725-741.

9. Muttini A, Russo V, Rossi E, Mauro Mattioli, Barbara Barboni, et al. (2015) Pilot experimental study on amniotic epithelial mesenchymal cell transplantation in natural occurring tendinopathy in horses. Ultrasonographic and histological comparison. Muscles Ligaments Tendons J 5(1): 5-11.

10. Mauro A, Russo V, Di Marcantonio L, Paolo Berardinellia, Alessandra Martelli, et al. (2016) M1 and M2 macrophage recruitment during tendon regeneration induced by amniotic epithelial cell allotransplantation in ovine. Res Vet Sci 105: 92-102.
11. Shandley L, Alcorn D, Wintour EM (1997) Ovine amniotic and allantoic epithelia across gestation. Anat Rec 248: 542-553.

12. Alcaraz A, Mrowiec A, Insausti CL, García Vizcaíno EM, Ruiz Canada C, et al. (2013) Autocrine TGF- BInduces Epithelial to Mesenchymal Transition in Human Amniotic Epithelial Cells. Cell Transplant 22: 1351-1367.

13. Caruso M, Evangelista M, Parolini O (2012) Human term placental cells: phenotype, properties and new avenues in regenerative medicine. Int J Mol Cell Med 1(2): 64-74.

14. Jeon SY, Hwang KA, Choi KC (2016) Effect of steroid hormones, estrogen and progesterone, on epithelial mesenchymal transition in ovarian cancer development. J Steroid Biochem Mol Biol 158: 1-8.

15. Van der Horst PH, Wang Y, Vandenput I, Kühne LC, Ewing PC, et al. (2012) Progesterone Inhibits Epithelial-toMesenchymal Transition in Endometrial Cancer. PLoS One 7(1): E30840.

16. Sumida T, Yoko Itahana, Hiroyuki Hamakawa, Pierre Yves Desprez (2004) Reduction of Human Metastatic Breast Cancer Cell Aggressiveness on Introduction of Either Form A or B of the Progesterone Receptor and Then Treatment with Progestins. Cancer Res 64: 7886-7892.

17. Zuo L, Li W, You S (2010) Progesterone reverses the mesenchymal phenotypes of basal phenotype breast cancer cells via a membrane progesterone receptor mediated pathway. Breast Cancer Res 12(3):34

18. Miscia S, Ciccocioppo F, Lanuti P, Velluto L, Bascelli A, et al. (2009) A $\beta 1-42$ stimulated T cells express P-PKC- $\delta$ and P-PKC- $\zeta$ in Alzheimer disease. Neurobiol Aging 30(3): 394-406.

19. Hyttel P, Sinowatz F, Vejlsted M, Keith Betteridge (2010) Essential of Domestic Animal Embryology (1 ${ }^{\text {st }}$ Edn.). In Hyttel P, Sinowatz F, Vejlsted M, Keith Betteridge (Eds.), Clim Chang 2013 - Phys Sci Basis.

20. Martinovic V, Vukusic Pusic T, Restovic I, Ivana Bocina, Natalija Filipovic, et al. (2017) Expression of Epithelial and Mesenchymal Differentiation Markers in the Early Human Gonadal Development. Anat Rec 1-35.

21. Lee K, Nelson CM (2012) New Insights into the Regulation of EpithelialMesenchymal Transition and Tissue Fibrosis. Int Rev Cell Mol Biol 294: 171-221.

\section{ISSN: 2574-1241}

DOI: 10.26717/BJSTR.2018.06.001400

Hashimita Sanyal. Biomed J Sci \& Tech Res

This work is licensed under Creative

Commons Attribution 4.0 License

Submission Link: https://biomedres.us/submit-manuscript.php

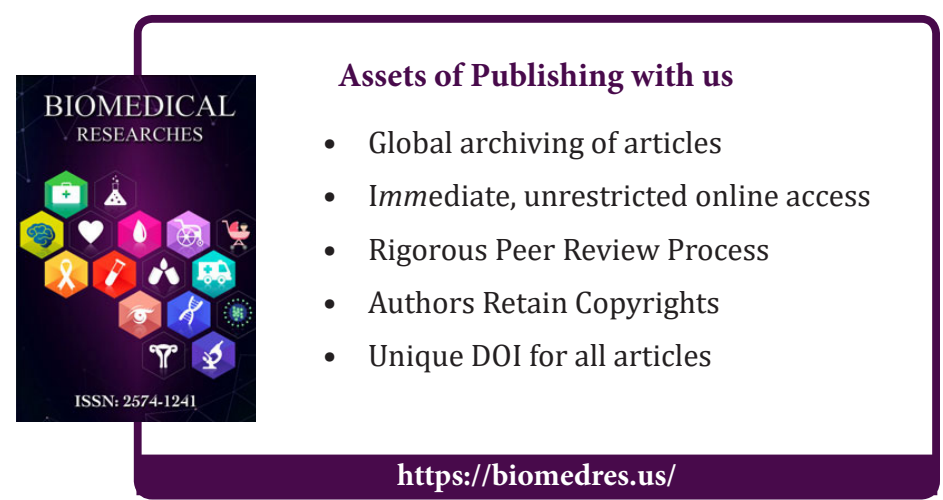

Cite this article: Hashimita S, Annunziata M, Valentina R, Paolo B, Angelo C, et.al. Protocol for the Ovine Amniotic Epithelial Cell In Vitro

Culture and Differentiation. Biomed J Sci\&Tech Res 6(4)- 2018. BJSTR. MS.ID.001400. D0I: 10.26717/ BJSTR.2018.06.001400. 